NIST Technical Note 2086

\title{
A Review of Social Media Use During Disaster Response and Recovery Phases
}

Camila E. Young Erica D. Kuligowski

Aashna Pradhan

This publication is available free of charge from: https://doi.org/10.6028/NIST.TN.2086

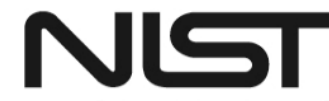

National Institute of Standards and Technology U.S. Department of Commerce 


\section{NIST Technical Note 2086}

\section{A Review of Social Media Use During Disaster Response and Recovery Phases}

Camila E. Young

Erica D. Kuligowski

Aashna Pradhan

Fire Research Division

Engineering Laboratory

This publication is available free of charge from:

https://doi.org/10.6028/NIST.TN.2086

January 2020

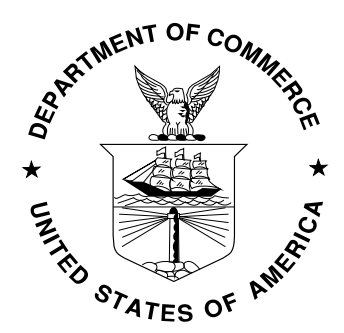

U.S. Department of Commerce Wilbur L. Ross, Jr., Secretary

National Institute of Standards and Technology Walter Copan, NIST Director and Undersecretary of Commerce for Standards and Technology 
Certain commercial entities, equipment, or materials may be identified in this document in order to describe an experimental procedure or concept adequately. Such identification is not intended to imply recommendation or endorsement by the National Institute of Standards and Technology, nor is it intended to imply that the entities, materials, or equipment are necessarily the best available for the purpose.

National Institute of Standards and Technology Technical Note 2086

Natl. Inst. Stand. Technol. Tech. Note 2086, 43 pages (January 2020)

CODEN: NTNOEF

This publication is available free of charge from:

https://doi.org/10.6028/NIST.TN.2086 


\begin{abstract}
Under the National Construction Safety Team Act, the National Institute of Standards and Technology (NIST) investigated the May 22, 2011 tornado in Joplin, Missouri. The investigation was an effort to characterize (1) the wind environment and technical conditions associated with fatalities and injuries, (2) the performance of emergency communications systems and the public response to such communications, and (3) the performance of residential, commercial, and critical buildings, designated safe areas in buildings as well as lifelines.

The final report of the investigation concluded with a list of sixteen recommendations, including but not limited to recommendations for action on emergency communications. Specifically, NIST recommended "the development of national codes and standards and uniform guidance for clear, consistent, recognizable, and accurate emergency communications, encompassing alerts and warnings, to enable safe, effective, and timely responses" [1, p.367].

This Technical Note is the third installment in the NIST effort to develop evidence-based guidance on the creation and provision of public alerts. The first publication in this series, “Outdoor Siren Systems: A review of technology, usage, and public response during emergencies," provided both an outline on the current status of outdoor siren systems in the U.S., as well as a literature review of how people respond to these systems [2]. The second Technical Note, "A review of public response to short message alerts under imminent threats,” focused on short message alerts, underscoring best practices as well as strategies geared towards improving message design and delivery, based on the methods by which people receive and process these types of alerts [3].

In this publication, first we present an overview of current popular social media platforms and the capabilities that they feature, as well as their potential applications for emergency management. That is followed by an outline of social media use for disaster response and recovery research findings, organized by themes. The response themes relate to: 1) the use of these tools for formal emergency management, 2) innovative social media applications for disaster response, and 3) how the general public uses these platforms. The recovery themes involve: 1) social media during recovery for mental health, 2) recovery assessment, and 3) relationship development post-event. The research findings are followed by the limitations and practical considerations for emergency managers, as well as future research suggestions.
\end{abstract}

\title{
Keywords:
}

Disaster communication; disaster recovery; disaster response; emergency management; Facebook; Instagram; social media; strategic communication; Twitter. 


\section{Table of Contents}

1. Introduction and Purpose ....................................................................................................1

1.1. Background: U.S. Emergency Management and the Disaster Lifecycle ...................2

1.2. Background: Social Media Use During and After Disasters ...............................4

2. Technical Note Organization and Methods..................................................................6

3. Current Status of Social Media Use for Disaster Response .........................................7

3.1. Current Formal Use of Social Media for Disaster Response ................................

3.2. Potential Use of Social Media for Disaster Response .........................................9

3.3. Current Public Use of Social Media for Disaster Response ................................10

3.4. Summary of Findings on the Use of Social Media for Disaster Response...............12

4. Current Status of Social Media Use During Disaster Recovery .............................15

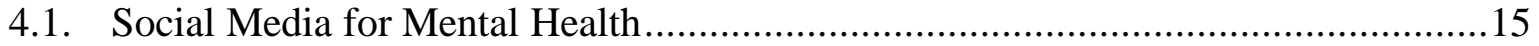

4.2. Social Media for Disaster Recovery Progress Assessment ..................................16

4.3. Social Media for Post-Disaster Relationship Development ................................17

4.4. Summary of Findings on the Use of Social Media for Disaster Recovery...............19

5. Limitations of Social Media for Disaster Response and Recovery ..........................22

6. Practical Considerations for Social Media Use for Response and Recovery ...........23

6.1. Practical Considerations for Disaster Response .............................................23

6.1.1. Application of Current Best Practices ...........................................................23

6.1.2. Innovation Opportunities ......................................................................24

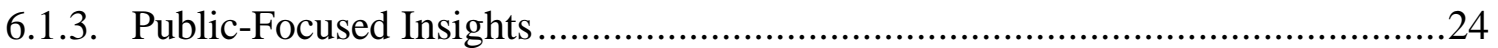

6.2. Practical Considerations for Disaster Recovery..............................................25

6.2.1. Post-Disaster Mental Health and Coping.....................................................25

6.2.2. Recovery and Reconstruction Assessment ..................................................26

6.2.3. Relationship Management ..................................................................26

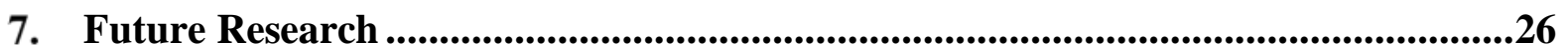

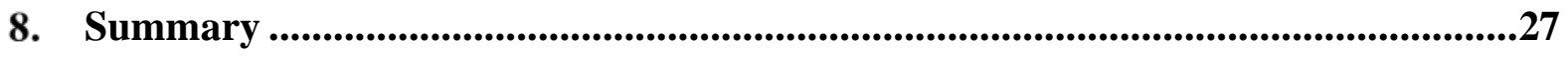

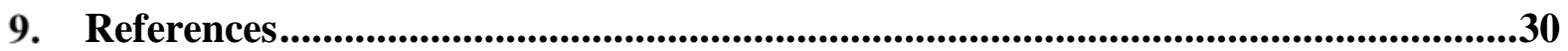




\section{Introduction and Purpose}

Tornadoes pose a significant threat to life and property in the U.S. In an average year, they are responsible for the most fatalities and insured losses of any natural hazard in the U.S. For example, from 2001 to 2010, the U.S. averaged nearly \$1B in insured losses and 56 fatalities per year from tornadoes according to the National Oceanic and Atmospheric Administration (NOAA) [4]. One of the deadliest U.S. tornadoes on record struck the city of Joplin, MO and the surrounding areas on May 22, 2011.

The tornado that occurred on May 22, 2011 in Joplin, Missouri, was rated as a National Weather Service (NWS) EF-5 tornado on the Enhanced Fujita tornado intensity scale [5]. This tornado touched down just to the west of Joplin and proceeded to cut a swath across the entire city. The tornado directly affected 41 percent of the city's population (20 820 people, out of the 50,175 estimated), damaged or destroyed nearly 8,000 structures and caused nearly \$2B in insured commercial and residential property losses and generated approximately 2.29 x 106 m3 (3M yd3) of debris [1]. More importantly, the structural damage and associated windborne debris were responsible for the majority of the 161 fatalities, the most caused by a single tornado since the NWS started keeping records in 1950. Windborne debris was also a major factor in the over 1000 injuries reported from the tornado, which also included many debris impacts.

Given the unprecedented number of fatalities and injuries, as well as the scope and extent of structural damages caused by the Joplin tornado, the National Institute of Standards and Technology (NIST) formally established a team to investigate the disaster under the National Construction Safety Team (NCST) Act (Public Law 107-231). The team consisted of the four NIST researchers with expertise in structural and fire engineering, wind science and engineering, and sociology, as well as a researcher from the NOAA's National Severe Storms Laboratory (NSSL) with expertise in meteorology, severe storms, and warnings.

The NIST Investigation's goals were to: (1) study the wind environment and conditions associated with fatalities and injuries, the performance of emergency communications systems and public response to such communications, and the performance of residential, commercial, and critical buildings (e.g., hospital), designated safe areas in buildings, and lifelines; and (2) develop findings and recommendations that serve as the basis for potential improvements to public safety in tornadoes, including:

- Potential improvements to requirements for design and construction of buildings, designated safe areas, and lifeline facilities in tornado-prone regions;

- Potential improvements to guidance for tornado warning systems and emergency response procedures; and

- Potential revisions to building, fire, and emergency communications codes, standards, and practices.

Several findings from this investigation focus specifically on emergency communications [1]. The finding most relevant to this study was that no widely accepted standards existed for emergency communications in tornado events. In response to these findings from the investigation, NIST recommended "the development of national codes and standards and 
uniform guidance for clear, consistent, recognizable, and accurate emergency communications, encompassing alerts and warnings, to enable safe, effective and timely responses” [1].

With the extensive use of outdoor siren systems in tornado prone areas and the increasing use of social media and other mobile platforms, the three Technical Notes were published with the goal of creating evidence-based guidance for communities on the creation and provision of public alerts. First, in 2017, a NIST Technical Note was published on outdoor siren systems [2]. This Technical Note provided an overview on the current status of siren systems in the U.S., as well as a review of the literature on how people responded to alerting signals (including siren systems) and the current limitations of siren systems considering these findings.

In 2018, NIST published the second Technical Note focused on public response to short message alerts while under imminent threat [3]. The document provided an overview on the current status of short message alerting, focusing on Wireless Emergency Alerts (WEAs) and Twitter alerts; research findings on how the public responds to short message alerts; and suggestions for improving current short message alerts, based on the methods by which people receive and process alerts. From these two review documents [2, 3], evidence-based guidance was developed for communities on the creation and provision of public alerts, including both alerts provided by outdoor siren (warning) systems and "short messages" sent by social media or other short message service (SMS) platforms [6].

This current document is also designed to develop evidence-based communication guidance, this time focused on social media use during disaster response and recovery phases for emergency management functions. The development of these guidelines is underscored by a review of the literature of the current status of social media use during these disaster phases, in addition to an overview regarding the potential opportunities as well as challenges of employing social media tools for emergency management functions. This report ends with practical considerations for social media best practices for emergency management purposes.

\subsection{Background: U.S. Emergency Management and the Disaster Lifecycle}

The disaster life cycle is a framework typically employed in emergency management to delineate the different stages of a developing disaster event. Its main purpose is to tie the temporal dimension of an emergency with the appropriate functions for its successful management. The origin of the disaster life cycle is credited to a 1979 Emergency Preparedness Project report developed by the National Governors’ Association [7, 8]. The report organized emergency management activities into four categories based on their temporal and functional relationship with the disaster: mitigation, preparedness, response, and recovery. Table 1 illustrates the four disaster stages and their corresponding functions as presented in the Emergency Preparedness Project [8]: 
Table 1. Emergency Management Phases Definition and Activities (Adapted from the National Governors’ Association’s 1979 Report [8])

\begin{tabular}{|c|c|c|}
\hline Disaster Phase & Definition & Activities \\
\hline Mitigation & $\begin{array}{l}\text { The initial phase, the one which occurs } \\
\text { earliest before a disaster. Includes } \\
\text { activities that eliminate or reduce the } \\
\text { probability of the occurrence of a disaster. }\end{array}$ & $\begin{array}{l}\text { Developing and implementing building } \\
\text { standards. Establishing communication } \\
\text { systems, and emergency operations centers. } \\
\text { Conducting hazard and vulnerability } \\
\text { analyses, etc. }\end{array}$ \\
\hline Preparedness & $\begin{array}{l}\text { Set of activities closest to the onset of a } \\
\text { disaster. These activities minimize disaster } \\
\text { damage and enhance disaster response } \\
\text { operations }\end{array}$ & $\begin{array}{l}\text { Enacting emergency procedures and } \\
\text { prevention measures. Conducting exercises. } \\
\text { Planning. Forecasting. Educating } \\
\text { government officials and other emergency } \\
\text { management stakeholders (i.e., federal, state } \\
\text { and local government, individuals, private } \\
\text { voluntary organizations, businesses, etc.). }\end{array}$ \\
\hline Response & $\begin{array}{l}\text { Activities that most closely follow disaster } \\
\text { impact designed to provide emergency } \\
\text { assistance for disaster casualties, reduce } \\
\text { the probability of secondary damage, and } \\
\text { speeding recovery operations. }\end{array}$ & $\begin{array}{l}\text { Engaging in search and rescue operations. } \\
\text { Seeking shelter. Shutting down utilities that } \\
\text { experienced systemic damage. Making } \\
\text { damage assessments. Disaster declarations. }\end{array}$ \\
\hline Recovery & $\begin{array}{l}\text { Activities that continue beyond the } \\
\text { emergency period immediately following a } \\
\text { disaster. Their purpose is to return all } \\
\text { systems to normal operating levels. }\end{array}$ & $\begin{array}{l}\text { Insurance. Reconstruction. Welfare. } \\
\text { Individual and organizational financial } \\
\text { assistance. Clean-up and temporary shelters. } \\
\text { Redevelopment loans, legal assistance and } \\
\text { community planning activities. }\end{array}$ \\
\hline
\end{tabular}

Since the publication of the 1979 report [8], there have been several key events that have further shaped the way emergency management is approached in the U.S., including the 2001 World Trade Center Disaster. Contemporary emergency management principles are rooted in the policy changes that resulted from this event.

For example, according to a working paper by the National Hazards Center at the University of Colorado at Boulder [9], the number of legislative and policy changes that were enacted in the eighteen months following the September 11 attacks is greater than the changes of the previous eighteen years combined. As a result of these policy changes, the U.S. federal government places a greater emphasis on terrorist attacks in its emergency management framework. In 2011, the Obama administration developed the Presidential Policy Directive 8 (PPD-8) [10], National Preparedness, which is aimed at:

“...strengthening the security and resilience of the U.S. through systematic preparation for the threats that pose the greatest risk to the security of the Nation, including acts of terrorism, cyber-attacks, pandemics, and catastrophic natural disasters" [10].

Shortly following the release of the PPD-8, the Department of Homeland Security (DHS) presented the first deliverable required under the new directive, the National Preparedness Goal [11]. The goal articulates the core capabilities and organizes them by five mission areas. 
Like the 1979 Governors' Association disaster life cycle description, the mission areas of the National Preparedness Goal also include mitigation, response and recovery. However, the National Preparedness Goal introduces new mission areas: Protection and Prevention and labels the entire process as "preparedness."

This revised emergency management framework organizes its respective functions into the following mission areas:

- Prevention. Prevent, avoid or stop an imminent, threatened or actual act of terrorism (and human-caused or natural disasters).

- Protection. Protect our citizens, residents, visitors and assets against the greatest threats and hazards in a manner that allows our interests, aspirations and way of life to thrive.

- Mitigation. Reduce the loss of life and property by lessening the impact of future disasters.

- Response. Respond quickly to save lives, protect property and the environment, and meet basic human needs in the aftermath of a catastrophic incident.

- Recovery. Recover through a focus on the timely restoration, strengthening and revitalization of infrastructure, housing and a sustainable economy, as well as health, social, cultural, historic and environmental fabric of communities affected by a catastrophic incident [12].

While there are 5 main mission areas, this report focuses exclusively on the response and recovery phases. These stages of the disaster life cycle are characterized by critical information needs that can be unforeseen due to the unpredictable nature of disasters and emergencies. It is at that juncture when the insight from social media can be instrumental to emergency managers crunched for time and resources. To effectively reap the supposed benefits of this technology, then, a stronger understanding of the current opportunities and challenges of social media use in these contexts is needed. To that end, the following section presents an introductory overview of these platforms and the underlying motivations for their use during disasters.

\subsection{Background: Social Media Use During and After Disasters}

Social media is commonly used to describe different types of web-based platforms. Certain researchers suggest that social media includes Internet-based applications characterized by the fact that, in some form or another, all of its users are able and encouraged to create, share and interact with user-generated content in a participatory and collaborative way [13]. Other scholars in this area sometimes refer to social media as "social networking sites" (SNSs), defined as:

“...web-based services that allow individuals to (1) construct a public or semi-public profile within a bounded system, (2) articulate a list of other users with whom they share a connection, and (3) view and traverse their list of connections and those made by others within the system" [15, p.211].

There are many different types of platforms that can be considered social media, and just as many configurations for the way in which its users can connect with one another. According 
to boyd and Ellison, the earlier versions of what we now call social media were created in 1997 [14]. The more widely adopted and recognizable platforms - such as MySpace, Facebook and Twitter - came to be in 2003, 2004 and 2006, respectively. Over the years, these and many other platforms have adapted to suit both the changing needs of their users as well as the interests of the developers that design them.

Social media platforms have transformed the way in which people meet, stay in contact and connect, all through a computer-mediated environment. In addition to everyday use, people turn to social media platforms before, during and after disasters. According to a report developed by the National Consortium for the Study of Terrorism and Responses to Terrorism (START) [15], social media use by the general public ${ }^{1}$ during disasters is due to convenience, social norms, and personal recommendations. Also, in times of disaster events, people use social media for humor and levity, to determine disaster magnitude, to check in with people in their networks, to self-mobilize, to maintain a sense of community, and to seek emotional support and healing [16, p.4].

Another driver for social media use during disasters involves information seeking [15]. Fraustino et al. [15] stress that despite certain concerns over information accuracy and validity, members of the general public still turn to social media to search for timely and unfiltered information. Additionally, emergency managers also recognize the opportunities that these tools represent for effective emergency management across all stages of the disaster life cycle.

As users began to employ social media platforms during disasters, developers then integrated features that further encouraged the use of these platforms in an emergency context. For example, Facebook currently offers four crisis support features: Safety Check, Community Help, Fundraisers and Crisis Response. Safety Check allows Facebook users to notify other users in their networks that they are "safe" in the wake of an ongoing disaster [18]. Community Help enables users to seek and/or offer help in a variety of ways during disasters, like finding and providing shelter, food and supplies [19]. Also, the Fundraisers feature supports fundraising campaigns for many types of causes, including losses during disasters [19]. Finally, Crisis Response works as a hub where users can locate all the previously mentioned features in one place, while also providing a channel where users can read and find publicly available disaster-related posts, links, photos, and audio-visual recordings [20].

Other social media platforms also provide emergency management support. For example, YouTube users can upload and share disaster-related videos [21], often capturing the actual experiences of those who are affected by disasters [22]. Research shows that after disasters, YouTube can be used to share complex information in addition to more light-hearted content that helps relieve disaster-related stress [23]. Even image-based social media platforms - like

\footnotetext{
${ }^{1}$ Per the West's Encyclopedia of American Law (2008), the public refers to "the whole body politic, or the aggregate of the citizens of a state, nation or municipality" [16]. Related to the concept of the public is the term audience, which describes "a large number of unidentifiable people, usually united by their participation in media use. Given the varying demographics of this group, not to mention variations between nations, the concept itself is a means by which such an unknowable group can be imagined” [17]. In the context of this Technical Note, public refers to the aggregate social media users that are spatially bound to an at-risk area. Not every individual of the atrisk population is online or even reachable through these social media platforms. Similarly, not all social media users engaged in consuming, generating and sharing disaster-related content online are physically at-risk of being affected by the disaster.
} 
Flickr ${ }^{2}$ and Instagram - can help emergency managers track disaster damage impact as well as recovery processes [24].

Apart from social media platforms, mobile applications can also provide emergency management support. In the U.S., emergency managers can use the FEMA application to provide at-risk public with real-time NWS alerts, safety tips, and locations of operational shelters [25]. "Harmany" is an application that can connect people who can provide shelter during a disaster with those in need [26]. Another example is “Zello," an Internet-based walkie-talkie or push-to-talk application that gained prominence when civilian rescue groups deployed it for emergency search, rescue, and recovery efforts during Hurricane Harvey [27]. Communities can make use of applications like "Nextdoor," which allows neighbors to connect with one another in "private online communities" [28]. During a disaster, "Nextdoor" users can leverage the application to find and share resources, share updates and distribute information, and to ask as well as offer help [29].

\section{Technical Note Organization and Methods}

This Technical Note presents a summary of research intended to inform both communities and emergency managers on employing social media tools for effective disaster response and recovery functions. Chiefly, it answers the following questions concerning social media use during different stages of the disaster life cycle

1. What is the current status of social media use for disaster response, including use by the general public and potential challenges associated with that use?

2. What is the current status of social media use for disaster recovery, including use by the general public and potential challenges associated with that use?

To answer both research questions, a literature review was conducted. The main objective of this review was to identify relevant and recent research at the intersection of social media use and disaster response and recovery processes. A general search for literature in this area was performed, and studies that met the selection criteria were collected for analysis. The selection criteria for the studies considered for this report were based on whether they met the following criteria:

- published in either a peer-reviewed journal or as part of published conference proceedings,

- $\quad$ published within the 2015-2019 timeframe,

- explicitly addressed the use of social media during the disaster response and/or recovery phases,

- available in the English language, and

- contained original data; i.e., did not consist solely of systematic literature reviews of studies about social media use during disasters.

A total of 48 relevant sources were collected and reviewed as part of this report. The selected studies are intended to present a representative, as opposed to exhaustive, perspective

${ }^{2}$ Flickr is a photo-sharing social media platform. It provides its users with many features like customizable privacy settings for each individual photo, and a large amount of storage space for uploading photos. 
concerning recent research and applied considerations for social media use during disaster response and recovery. The following databases were used to collect literature: Google Scholar, Web of Science, and EBSCOhost - with a combination of the following keywords: disaster response, disaster recovery, social media, disaster information, Twitter, Facebook, disaster management, and social network.

Once potential articles were initially identified through the keyword search in the databases, the studies' abstracts were used to distinguish between relevant and irrelevant articles according to the above-listed criteria.

Most of the collected publications focused on specific human-caused and natural hazards, including wildfires, earthquakes, hurricanes, typhoons, tsunamis, tornadoes, floods, snow storms, and bombings. However, in some cases, no specific disaster contexts were chosen. Some explored the use of social media for post-disaster emergency response through in-depth interviews and surveys [30-33] and others explored the use of social media for post-disaster temporary memorializing, journalists' use of social media, or approaches to bridging the gap between emergency managers and the public [34-36]. Finally, other studies - most notably the ones conducted by Wukich and Mergel [37], and Dutt et al. [38] - looked at more than one disaster event.

\section{Current Status of Social Media Use for Disaster Response}

The disaster response phase is characterized by damage assessment as well as immediate efforts to preserve life and infrastructure. Three themes were identified as emerging from literature on disaster response: the current use of social media, the potential for its uses in the future, and the ways in which the general public currently uses social media platforms. Each theme will be described in the following sections, with supporting literature.

\subsection{Current Formal Use of Social Media for Disaster Response}

The first theme involves the current use of social media for disaster response on behalf of emergency management entities. In this review, emergency management entities include law enforcement agencies [17, 19, 26], civil defense agencies [39], county-level emergency management directors or coordinators [33], federal agencies such as the NWS [40], fire department/officials and Red Cross volunteers [32], and the emergency medical service [30].

Entities at the local, state, and federal level share a responsibility to prepare for and respond to emergencies, and communication is a crucial function of this responsibility. During a disaster, emergency managers communicate amongst themselves, as well as with news media organizations, journalists, and the general public. Social media is a tool that emergency managers can leverage to communicate with these different stakeholders. However, less is known about how and to what extent emergency managers actually use social media in their disaster response efforts. Studies within this theme focus on outlining current social media uses, usage barriers, and potential solutions to those challenges. 
Studies provide evidence that social media has been used by government officials during response to actual incidents. For example, during the 2015 Nepal Earthquake, the police used social media to share information and warnings, encourage protective behavior, seek information, and address rumors [41]. Similarly, Jordanian government officials also relied on Facebook during the 2018 Dead Sea flash flood to address rumors [39]. To address rumors concerning the condition of a dam and possibilities of flooding, the dam's supervisor quickly posted status updates and pictures that supported his statements. Additionally, Facebook Live was used by civilian bystanders to update the General Directorate of Jordan Civil Defense on flood-affected areas in real-time [39]. From there, volunteers received instructions from authorities, facilitating two-way communication.

In the U.S., one study documents social media use by NOAA's NWS [40]. While the federal agency develops social media messages to engage in community-building efforts pre-event, NWS shifts its social media messaging strategy when severe weather is imminent. The content analysis conducted by Olson et al. [40] found that during periods of weather risk, the NWS focused on sharing messages that addressed current and ongoing weather conditions and presented weather products. Further, the NWS was more likely to engage with the public (i.e., replying to users' comments) during periods of severe weather.

Other studies focus on emergency managers' perceptions of social media use for disaster response. For example, a survey of U.S. county-level emergency managers [33] revealed that while emergency managers acknowledged the usefulness of these tools, perceived barriers limited their application in response efforts. These obstacles included the following: (1) a lack of social media guidelines for usage, (2) a lack of staff and resources dedicated to these platforms, (3) a lack of trust in the accuracy of the information from these sources, and (4) issues surrounding information overload. Possibly because of these barriers, current usage of social media tools by emergency managers focuses mainly on providing specific information to the public (one-way), including posting public alerts and reassurances, engaging in public relations efforts and countering rumors/misinformation. Similarly, a study of Norwegian emergency managers found that social media was mostly used as a one-way communication channel for sharing public updates [32]. This study also revealed a lack of confidence in the information that could be gleaned from these channels. This lack of trust in user-generated social media content was also evident in a study of Swedish emergency managers [30].

These studies often conclude with recommendations to address the major challenges of social media use for disaster response. The main challenge is that social media is not currently an organizational capability within emergency management. Although methods for using these tools have been created, they are used by emergency officials in a limited capacity [30, 33]. Studies suggest that stakeholders could benefit from technological advancements that can solve the issues of data vetting and information overload [30] as well as provide more efficient platforms that can retrieve information from social media [32]. As it stands, efforts to develop such technologies and platforms are the focus of the following theme: "potential use of social media for disaster response.” 


\subsection{Potential Use of Social Media for Disaster Response}

The second theme focuses on potential or experimental social media applications. In this section, studies describe tools developed by researchers to extract insight from disasterrelated social media content to better inform emergency officials on the coordination and execution of disaster response efforts. In these cases, social media content can be created by and shared by different stakeholders, including emergency managers, media, and the general public.

First, obtaining insights (e.g., for situational awareness) from large social media datasets is possible through machine learning. Machine learning is an algorithm or model that learns patterns in data and then predicts similar patterns in new data [42]. There are different types of machine learning approaches, like supervised machine learning, i.e., a data mining task that involves inferring a function from labeled training data [43]. Using social media data as an example, a supervised machine learning approach requires a training dataset of social media posts that have already been coded with the categories of interest. By providing examples of how different types of posts can be categorized, the supervised machine learning algorithm can then apply the coding scheme it infers on new datasets. For example, Li et al. [44] developed a machine learning technique based on domain adaptation that can use labelled training data from one disaster to inform the classification of data from a different disaster. Their results suggest that for general categories easily applicable to different disaster types, researchers can use the labelled data of a previous disaster (in this case, Hurricane Sandy) to classify data from a new disaster (e.g., the Boston Marathon Bombing) [44].

While this approach solves some of the issues associated with manual coding of social media posts, there is still much work to be done on this front. More research is needed to explore if the categories inferred from one disaster type may be applicable to other disaster types outside of the hurricane/bombing events used in the Li et al. [44] study.

Even with machine learning techniques in place, it will still be necessary to develop userfriendly mechanisms that make the task of collecting, filtering, categorizing, and visualizing social media data a realistic enterprise for emergency managers. Therefore, researchers and emergency managers across Europe are collaborating to develop a user-friendly technology that can capitalize on the insights provided by social media. While tests of the interface's functionality suggest that there is still work to be done, this study shows that tools and techniques to optimize information extraction from social media platforms are under development [31].

Work is also ongoing in the U.S. to create social media data gathering, filtering, and visualization tools. The U.S. DHS Science and Technology Center of Excellence (COE) Purdue University's Center for Visualization and Data Analytics (CVADA) - has created a Social Media Analytics and Reporting Toolkit (SMART) solution. SMART "is an interactive web-accessible system that provides users with aggregated social media data (e.g., Twitter and Instagram) for analysis and visualization" [45]. The tool has been used by a variety of emergency management stakeholders and deployed in different types of scenarios [46]. 
Additional studies showcase specific topics where social media data can provide added situational awareness in disaster response [47, 48]. For example, social media data could help to supplement rainstorm and floods precipitation data [49], peatland fires and haze events [50], and official inundation maps [51]. Further, tweets can provide potential insight about the travel patterns of social media users located in the affected areas [50]. Social media can also provide emergency managers with information on resource needs and resource availability, and in turn, match those needs with the available resources [38], including rescue personnel and volunteers [52].

It is also important for emergency managers to understand the needs of the public during disaster events. In their study of the 2018 Camp Fire (California, U.S.), Du et al. [53] found that social media users and news media organizations focused on different aspects of the wildfire. Specifically, the content shared by social media users conveyed a stronger interest in rescue-related matters; whereas news media discussed wildfires in more general terms. This finding aligns well with previous work that underscores the differences between mainstream news coverage and the types of information that is of interest to affected communities [54].

Taken together, these studies illustrate that the strength of social media for disaster response lies in distilling insight from vast amounts of data - which is now possible due to machine learning approaches. Furthermore, researchers have also embraced the challenge of developing user-friendly mechanisms that make the task of collecting, filtering, categorizing, and visualizing social media data a realistic enterprise for emergency managers. These attempts are not without their fair share of limitations - since developing a tool with general presets for different types of disasters and emergencies is still an ongoing effort. Better understanding of how affected communities are using social media during and shortly after a disaster can inform this endeavor in a more comprehensive way. The next theme focuses on broadening our understanding of how the public is currently using these platforms during and after disasters.

\subsection{Current Public Use of Social Media for Disaster Response}

Social media platforms encourage practitioners and researchers to acknowledge the more participatory role that civilians can now play in disaster response and recovery. This theme contributes to our current understanding of the social-mediated dynamics that emerge among public stakeholders during a disaster. Better understanding of who these stakeholders are, what kind of behaviors they engage in, and which motivations drive their behavior is key to inform future organizational practices or policy that shape disaster response.

First, studies have characterized social media users who participate in disaster-related discussions. Users are primarily categorized based on professional and/or job positions, their communication behaviors, and their roles in online disaster-related information diffusion. For example, a content analysis conducted by Silver and Andrey [55] categorized Twitter users as weather experts, weather enthusiasts, first responders, media, and citizens, based solely on their bios. Further, when studying communication outcomes, they found differences in behaviors across users. For example, weather experts and weather enthusiasts were more 
likely to use regionally specific hashtags, create original content, have a large follower base, and have their content shared by other social media users. A content analysis conducted by Mirbabaie et al. [56] also characterized social media users by types based on posts from the 2017 Manchester bombing. More specifically, the role that people played in the crisis were organized into 11 convergence behavior archetypes (CBA), summarized in Table 2 below.

Table 2. Extant Convergence Behavior Archetypes

(Adapted from: Mirbabaie et al. [56], p.4).

\begin{tabular}{|c|c|c|}
\hline Behavior & Characteristics & Examples \\
\hline The Returnees & $\begin{array}{l}\text { Inquire about properties they left behind } \\
\text { and status updates about crises }\end{array}$ & $\begin{array}{l}\text { 'Back at my house. Whole area looks } \\
\text { devastated.' }\end{array}$ \\
\hline The Anxious & $\begin{array}{l}\text { Information seeking about missing persons, } \\
\text { shelter and medical aid or general } \\
\text { expression of fear }\end{array}$ & $\begin{array}{l}\text { 'Please, if anyone has seen my friend let me } \\
\text { know. We need to know she's okay!' }\end{array}$ \\
\hline The Helpers & $\begin{array}{l}\text { Help in identifying false crisis information, } \\
\text { create and share posts about possible } \\
\text { shelters }\end{array}$ & $\begin{array}{l}\text { 'If anybody needs a place to stay, message } \\
\text { me. I live nearby.' }\end{array}$ \\
\hline The Curious & $\begin{array}{l}\text { Ask questions about what happened and } \\
\text { crisis conditions }\end{array}$ & 'What happened? Anybody know?' \\
\hline The Exploiters & $\begin{array}{l}\text { Scamming or spreading of false } \\
\text { information, use crisis to promote own } \\
\text { organization/products }\end{array}$ & $\begin{array}{l}\text { Misuse of the crisis hashtag for own } \\
\text { products, e.g. '\#ManchesterBombing try } \\
\text { out our new product!' }\end{array}$ \\
\hline The Fans or Supporters & $\begin{array}{l}\text { Supportive and grateful social media posts } \\
\text { regarding disaster relief and official } \\
\text { rescuers }\end{array}$ & $\begin{array}{l}\text { 'Staff underpaid and overworked, but there } \\
\text { when we truly need them. Thank you.' }\end{array}$ \\
\hline The Mourners & $\begin{array}{l}\text { Paying tribute to victims or people affected } \\
\text { by the crisis }\end{array}$ & $\begin{array}{l}\text { 'Simply heartbroken by the news. Rest in } \\
\text { peace' }\end{array}$ \\
\hline The Detectives & $\begin{array}{l}\text { Surveillance activities, sharing news and } \\
\text { information to increase information } \\
\text { management }\end{array}$ & $\begin{array}{l}\text { 'Police operation after unconfirmed } \\
\text { gunshots and explosion.' }\end{array}$ \\
\hline The Manipulators & $\begin{array}{l}\text { Attention seeking and manipulative } \\
\text { behavior }\end{array}$ & $\begin{array}{l}\text { 'That proves I was right all along. They } \\
\text { should all be banned!' }\end{array}$ \\
\hline The Furious & $\begin{array}{l}\text { Expression of anger and resentment about } \\
\text { the crisis situation }\end{array}$ & $\begin{array}{l}\text { 'What a cowardly act of terror. This is } \\
\text { unbelievable!' }\end{array}$ \\
\hline The Impassive & $\begin{array}{l}\text { Don't actively take part in crisis } \\
\text { communication, "reportage" function }\end{array}$ & $\begin{array}{l}\text { e.g. passively sharing their own location } \\
\text { and incident details }\end{array}$ \\
\hline
\end{tabular}

Mirbabaie et al. [56] also categorized social media users by their activities on the platform; i.e., information starters, amplifiers, and transmitters. "Information starters" are those users that are the most retweeted, "amplifiers" are those that share or retweet content created by other users, and "transmitters" are the users that act as the bridge linking different online groups, communities, or networks together. Transmitters played a crucial role in online information diffusion across different networks. 
Additional studies focus instead on the kinds of content that social media users create and share during disasters. For example, a case study conducted by Slick [22] explored how affected communities used audiovisual content (e.g., static and mobile video cameras) to capture their lived experiences during the 2016 Fort McMurray wildfire in Alberta, Canada. Analysis of these videos identified three different types of lived experiences conveyed in these videos: "watching the wildfire approach the city", which focused on the movement and magnitude of the wildfire; "fleeing from the wildfire”, which captured evacuees' movements and behaviors; and "watching your house burn", which showed homes burning from inside or outside of the structure. Similarly, Bica et al. [57] conducted a content analysis of geotagged images posted during the Nepal earthquake in 2015. The results of the study suggested that social media users closer to the disaster impact area tended to retweet images that depicted relief, recovery, graphic visual, and structural damage information. In contrast, social media users from outside of the area focused more on images that depicted human suffering, as conveyed through their retweeting preferences.

Other studies explore why affected communities use social media during and shortly after a disaster. A case study of the 2011 Thailand Floods found that people used social media because other sources of information - such as mainstream news media and journalists - did not provide relevant or needed information [23]. This finding aligns well with existing research that suggests civilians use social media as a "backchannel" source for more granular information salient to them [54]. Other events have shown that social media was used to allow people access to different types of support during the event [58], including Facebook posts that conveyed gratitude, concerns, and complaints. Additionally, emergent groups can self-mobilize via social media platforms to provide information of specific interest to emergency managers [58].

\subsection{Summary of Findings on the Use of Social Media for Disaster Response}

The literature review of 22 recent disaster response articles yielded the following findings (organized by the three research themes/areas - current formal use, potential use, and general public usage):

\section{Current formal use:}

- $\quad$ Social media has been used to disseminate disaster warnings, mobilize volunteers and organizations, address rumors, and coordinate response and recovery [39, 41].

- Emergency managers use social media to communicate updates to the public and to monitor how other emergency managers use these platforms [32]. Also, entities use social media to provide weather watches and warnings to the public during periods of fair and severe weather [40].

- Incorporating civilian bystander reports from social media is currently not an organizational capability [30]. The top three reasons for not using social media during disasters to collect and share information are: insufficient staff, lack of confidence in information [32], and information overload [33]. 


\section{Potential use:}

- Social media can provide situational awareness to emergency managers, especially by mining geotagged disaster-related social media images [50]. Social media streams can be used to track the temporal progress of a disaster [49] or disaster damage assessments [48].

- Emergency managers can deal with the issues of information overload and quality of social media data with the help of tools designed for gathering and filtering social media data [31] or supervised machine learning techniques [44, 47].

- Social media can provide emergency managers with information on resource needs and resource availability and in turn match those needs with the available resources [38], including rescue personnel and volunteers [52].

- It is also important for emergency managers to understand the needs of the public in terms of disaster events [53].

\section{Public's use/capacities:}

- While social media users are unique, trends exist in how they use social media platforms during disasters [55, 56].

- Social media users share different types of content regarding the disaster [22], and the content can differ based on their location respective to the disaster impact area [57].

- Motivations for social media usage during disasters can also differ. Examples include providing and obtaining necessary information needed to manage the situation [23]; sharing information with emergency managers, and providing access to support services [58].

This section concludes with a summary of 22 research articles related to disaster response. Table 3 includes the study authors, the type of hazard(s) explored in the study, the specific disaster(s), the country where either the disaster or the study took place, the specific social media platform(s) studied, and the research method(s) employed. 
Table 3. Social Media Use During Disaster Response Research Summary Table

\begin{tabular}{|c|c|c|c|c|c|}
\hline Authors & Hazard Type & Disaster & Country & Social Media & Methods \\
\hline Alam et al. [47] & Hurricane & 2017 Hurricanes Harvey, Irma \& Maria & U.S. & Twitter & Machine Learning \\
\hline Banikalef et al. [39] & Flood & 2018 Dead Sea Flash Floods & Jordan & Facebook & n-Depth Interviews \& Thematic Analysis \\
\hline Bergstrand \& Stenmark [30] & N/A & N/A & Sweden & General & In-Depth Interviews \\
\hline Bica et al. [57] & Earthquake & 2015 Nepal Earthquakes & Nepal & Twitter & Content Analysis \\
\hline Du et al. [53] & Wildfire & 2018 Camp Fire & U.S. & Twitter & Machine Learning \\
\hline Dutt et al. [38] & Earthquake \& Flood & $\begin{array}{l}2015 \text { Nepal Earthquake } \\
2016 \text { Italy Earthquake } \\
2015 \text { Chennai Flood }\end{array}$ & $\begin{array}{l}\text { Nepal } \\
\text { Italy } \\
\text { India }\end{array}$ & Twitter & Machine Learning \\
\hline Fang et al. [49] & Flood & 2016 Wuhan Rainstorm \& Flood & China & Sina Weibo [59] & Information Extraction \\
\hline Kaufhold et al. [31] & N/A & N/A & Germany & Social Media & Survey \\
\hline Kibanov et al. [50] & Peatland Fire \& Haze & 2014 Sumatra Island Haze Event & Indonesia & Twitter & Spatiotemporal Analysis \\
\hline Kryvasheyeu et al. [48] & Hurricane & Hurricane Sandy & U.S. & Twitter & Spatiotemporal Analysis \\
\hline Lazreg et al. [32] & N/A & N/A & Norway & Social Media & In-Depth Interviews \\
\hline Leong et al. [23] & Flood & 2011 Thailand Floods & Thailand & Facebook, Twitter \& YouTube & Case Study \\
\hline Li et al. [44] & Hurricane \& Bombing & $\begin{array}{c}2012 \text { Hurricane Sandy \& } \\
2013 \text { Boston Marathon Bombing }\end{array}$ & U.S. & Twitter & Machine Learning \\
\hline Li et al. [51] & Flood & 2015 South Carolina Floods & U.S. & Twitter & Spatiotemporal Analysis \\
\hline Mirbabaie et al. [56] & Bombing & 2017 Manchester Bombing & England & Twitter & cial Network Analysis \& Content Analysis \\
\hline Nguyen et al. [52] & Hurricane & 2017 Hurricane Harvey & U.S. & Twitter & Machine Learning \\
\hline Olson et al. [40] & Several & 2016 3-Month Threat/Non-Threat Period & U.S. & Twitter & Content Analysis \\
\hline Plotnick et al. [33] & N/A & N/A & U.S. & Social Media & Survey \\
\hline Pyle et al. [58] & Snowstorm & 2014 Atlanta Ice Storms & U.S. & Facebook & Content Analysis \\
\hline Silver \& Andrey [55] & Tornado & 2016 Ontario Tornado & Canada & Twitter & Content Analysis \\
\hline Slick [22] & Wildfire & 2016 Fort McMurray Wildfire & Canada & YouTube & Phenomenological Reduction \\
\hline Subba \& Bui [41] & Earthquake & 2015 Nepal Earthquake & Nepal & Twitter & Content Analysis \\
\hline
\end{tabular}




\section{Current Status of Social Media Use During Disaster Recovery}

Disaster recovery is characterized by long-term reconstruction, restoration, and revitalization of affected communities after a disaster. The process of restoration includes but is not limited to "residents rebuilding homes or seeking new accommodations, businesses repairing and surviving lean times, utilities and public agencies repairing infrastructure and facilities, and households learning to cope with new stresses" [49, p.173]. Three themes were identified as emerging from literature on disaster recovery: the use of social media to achieve positive mental health outcomes, how social media can help in assessment of ongoing progress in post-event recovery, and how social media channels contribute to relationship building. Each theme will be described in the following sections, with supporting literature.

\subsection{Social Media for Mental Health}

Typically, disasters cause a range of unpleasant emotions. These emotions may be in response to a disaster's destructive capabilities and/or the social disruption and uncertainty that it causes. Despite the potential negative outcomes of disasters, people often respond to these events and the stressors that they precipitate in different ways. Research has shown that there is a myriad of factors that play an influential role in how well an individual is able to cope with disasters and trauma. According to the American Counseling Association [61], the factors that can affect people's coping skills during disasters include age, gender, socioeconomic status, and strength of social support systems.

In this context, social media can be used to assess post-disaster mood. Woo et al. [62] employed a natural language-processing and text-mining approach to explore changes in the public mood following the 2011 Sewol ferry disaster in Korea. As expected, the first five days following the event were characterized by a sharp increase in the prevalence of posts containing anger-related keywords. Although muted over time, the posts did not return to the baseline mood level observed prior to the event. Su et al. [63] tracked changes in a population's mood over time using machine learning techniques following the 2011 Fukushima Daiichi nuclear disaster in Japan. Like the trends observed in Woo et al. [62], posts revealed the post-event moods of the affected residents did not return to the pre-disaster base levels. These studies show the following: that social media content can provide realtime insight regarding predominant emotions of online users, that the negative emotional impact of a disaster can reach farther than the spatiotemporal dimensions of the impacted area, and the use of social media for assessing the moods of certain disaster populations is possible.

The use of social media as a mechanism to promote emotional wellness campaigns has also been explored. Calder et al. [64] evaluated the effectiveness of the "All Right?" wellbeing campaign developed by the Mental Health Foundation of New Zealand, a nonprofit organization, following the 2010-2011 Canterbury Earthquakes. Using a mixed-methodology approach of in-depth interviews and surveys, Calder et al. [64] found that the use of Facebook for promoting wellbeing messages during a disaster's recovery phase could have a positive impact on mental health outcomes. Specifically, Facebook users felt like part of a wider social network and the campaign motivated them to engage in recommended activities and behaviors. 
Additionally, social media use related to post-disaster memorializing has also been studied. Web-based memorializing is defined as "an emerging set of social practices mediated by computer networks, through which digital objects, structures, and spaces of commemoration are produced” [54, p.72]. Research in this area suggests that this phenomenon fulfills a communal function in which individuals can process their grief following a disaster event [65].

Research has outlined post-disaster temporary memorializing practices as considerations for disaster managers, specifically highlighting social media as an invaluable tool for supporting the recovery of affected communities [34]. In line with previous research, Whitton [34] observes that the Internet in general and social media allow people that do not or cannot visit temporary offline memorial sites to participate virtually. Social media also allows for the cathartic behavior of story-telling. Post-event storytelling; i.e., "telling stories about one's disaster experience, listening to other stories about the disaster" is a fundamental way for community members to engage collectively in the recovery process and become more resilient to future disasters [55, p.14].

\subsection{Social Media for Disaster Recovery Progress Assessment}

The second theme focuses on how social media can be used to monitor the progress of recovery. With many stakeholders, each with their own set of resources and responsibilities, populations are in constant need of information and updates. It is in this context that social media can provide insight into effective recovery planning and execution.

Social media data can provide recovery and relief managers with useful information. A study conducted by Huang and Xiao [67] presents a mechanism to mine social media data streams in order to then classify content into the different stages of emergency management (e.g., mitigation, preparedness, response, protection, and recovery), specifically identifying information that could increase emergency managers' situational awareness during recovery from Hurricane Sandy. Recovery information included business re-openings, cleanup procedures, work responsibilities, school status, re-entry after evacuation, return of infrastructure (Internet, gas, water, electricity, transportation etc.), restoration of goods and services, donation of money or goods, fundraising activities, state of infrastructure repair, and volunteering.

Social media data can also inform disaster recovery logistic assessments. Studies have used social media data from hurricanes to gauge evacuation patterns $[68,69]$ which can then help to predict return behaviors of evacuees [70]. Evacuation patterns and return behaviors are vital information for disaster recovery planning and decisions. Also, Jamali et al. [71] presented a model linking census tract-level information to geotagged social media content to draft recovery policies that could best address the specific needs of affected communities. Machine learning algorithms were developed to identify twitter users that experienced the disaster event, and in turn identify where these users might reside, what topics they discussed in a post-disaster setting, and how these aspects compared to users that did not experience the disaster directly. 
Research also suggests that social media is used as a mechanism to gauge recovery success or failure via indicators. For instance, Shibuya and Tanaka [72] explored the relationship between Twitter and Facebook content generated after the 2011 Great East Japan earthquake and tsunami and the demand for used vehicles as an indicator of socioeconomic recovery. Additionally, Yan et al. [24] suggested that geotagged social media data - such as pictures uploaded to Flickr - can be reliably employed as indicators of nascent tourism recovery in disaster-damaged areas, e.g., the Philippines after experiencing the Bohol Earthquake and Super Typhoon Haiyan in 2013.

\subsection{Social Media for Post-Disaster Relationship Development}

The third theme relates to the creation and maintenance of interpersonal relationships. That social media platforms have the potential to be used to create, maintain, and develop connections among different stakeholders before, during and after a disaster is not a new premise. However, the latest research in this area can illustrate to what extent that potential has been realized in the years since these tools were first presented. Furthermore, the collective insight of these experiences can also highlight potential areas of promise as well as prospective challenges.

Recent research findings show that social media affordances can be leveraged by emergency managers and relief nonprofit organizations to strengthen ties among one another during disaster recovery. A study conducted by Lai et al. [73] employed a social network analysis approach to explore the way in which relief organizations used social media affordances ${ }^{3}$ to build relationships with other nonprofit organizations. Following the Typhoon Haiyan in 2013, relief organizations used Facebook and Twitter to mention, tag, share, and retweet the content posted by other nonprofit relief organizations involved in typhoon-related recovery efforts, and these interactions supported the exchange of information and resources [73]. Similarly, Wukich and Mergel [37] found that U.S. state-level emergency management agencies tended to retweet content created by other government entities, and when sharing non-governmental sources, tended to rely on trusted and reliable sources like major nonprofit organizations (i.e., the American Red Cross). Overall, these results illustrate that while individual civilian perspectives may not be amplified on social media by government entities, emergency managers do vet information and share reliable content to their social-mediated networks. It is also important to note that inter-agency interactions are crucial to the growth and survival of organizations in an online environment, in that those who get tagged and mentioned stand to gain prominence in an environment competing for key publics' attention and support [73].

Social media is also seen as a method to bridge ties between emergency managers and those who can accomplish the recovery work. For example, Taylor et al. [74] studied relief networks that formed on Facebook following the major floods of a small Alaskan village in

\footnotetext{
${ }^{3}$ In this context, there are four social media features that contribute to this type of user-to-user engagement. The first feature is the capability to like, favor, or react to the content posted or shared by other users. The second feature is the capability to share (i.e., Facebook), retweet (i.e., Twitter), reblog (Tumblr), or otherwise essentially re-post the content that was posted or shared by another user. The third feature is the capability to comment on the content that was posted or shared by another user. Finally, the fourth feature is the capability to "tag" or "mention" other users in posts or comments.
} 
2013 and argue that social network analysis could be a suitable resource for identifying emergent users to function as a facilitator for local recovery efforts.

Other research suggests that social media can be used to facilitate relationships among emergency officials and community members [75]. Tagliacozzo [76] explored how government agencies used social media to share important recovery information with communities after the 2010/2011 Canterbury Earthquakes in New Zealand. The content shared through social media involved information related to traffic planning, housing and infrastructure reconstruction, psychosocial recovery, environmental risks, community groups, heritage preservation, damage assessments, volunteering and events, new policies, business recovery, funds, donations, education and health.

Social media approaches could result in mutually beneficial arrangements for communities seeking more agency in their recovery process and emergency managers seeking other sources of situational awareness [36]. However, there are still challenges associated with incorporating these platforms as part of disaster recovery efforts. For example, Tagliacozzo [76] identified the following emergency management obstacles for social media use during disaster recovery: lack of personnel, competing agency priorities, security issues, and a lack of policies and time. An additional concern involves the suitability of the channel for reaching target populations to provide them with the kind of detailed information needed for recovery. One of the government officials interviewed as part of the study noted that while social media is an effective tool for reaching a wider audience, the type of information shared as part of disaster recovery communication should be tailored to individual needs [76].

It was also important for organizations to recognize that the narrative tone they incorporate into their social media strategies influenced public perceptions [77].

Research also suggests that social media can foster relationships between affected communities and journalists during recovery. Research has found that U.S. journalists could act as facilitators between recovering communities and the agencies tasked with overseeing that process, as well as information providers to recovery entities on existing community needs and resources [35].

Finally, social media could be used to increase social capital among community members after a disaster [78, 79]. Social media platforms could assist recovering populations in developing a sense of community [80] and in turn manage their own recovery processes. Findings showcased that individuals with high social capital could use social media to secure the resources needed to recover from the effects of a disaster, but that more vulnerable and disenfranchised populations were less able to do so [81]. Notwithstanding, research also showed that social media allowed unconventional stakeholders to become prominent actors in the relief and recovery dynamics that played out between local communities and global supporters of these efforts [82]. 


\subsection{Summary of Findings on the Use of Social Media for Disaster Recovery}

The literature review of the 26 disaster recovery articles yielded the following findings (organized by the three themes - mental health, progress assessment, and relationship development):

\section{Mental Health:}

- Social media could be used to gauge the mood of certain sections of the affected population through social media sentiment analysis [62, 63].

- Social media could also be used to promote wellbeing messages as part of a disaster recovery mental health campaign [64].

- Social media provided a communal function in which individuals could process their grief following a disaster event, by providing a forum for story-telling [66] and an outlet for people to participate in memorial rituals virtually [34].

\section{Progress Assessment:}

- Social media platforms provided recovery and relief managers with useful information during the recovery process, including businesses re-openings, cleanup procedures, work responsibilities, school status, re-entry after evacuation, return of infrastructure, restoration of goods and services, donation of money or goods, fundraising activities, state of infrastructure repair, and volunteering [67].

- Social media could also inform disaster recovery logistic assessments, including evacuation and re-entry patterns key to recovery planning and decision-making [6870].

- Social media allowed emergency managers to distinguish among the needs of its users located within disaster-affected areas [71].

- Social media was also a mechanism to gauge recovery success via different indicators; e.g., the demand for used vehicles [72] or tourism rates in affected areas [24].

\section{Relationship Development:}

- Social media could help develop relationships between emergency managers and relief organizations through social media affordances (e.g., sharing, tagging and commenting functions) [37, 73].

- Emergency managers and agencies shared social media content created by trusted and credible sources [37].

- Facebook posts could help emergency managers identify existing needs and available resources for recovery [74].

- Emergency managers could use social media to facilitate relationships with community members by sharing information related to traffic planning, housing and infrastructure reconstruction, psychosocial recovery, environmental risks, community groups, heritage preservation, damage assessments, volunteering and events, new policies, business recovery, funds, donations as well as education and health during recovery $[36,75,76]$. 
- Although they recognized its benefits, emergency managers did not always have the resources or personnel to monitor and respond to recovery-related queries posted in social media [76].

- Social media could help journalists mediate recovery-focused discussions between affected communities and emergency managers [35].

- Social media could also assist in developing a sense of community and increase members' ability to manage their own recovery processes after a disaster event [7881]. Additionally, unconventional stakeholders could become prominent disaster recovery actors with the help of social media [82].

This section concludes with a summary of 26 articles related to disaster recovery. Table 4 includes the study authors, the type of hazard(s) explored in the study, the specific disaster(s), the country where either the disaster or the study took place, the specific social media platform(s) studied, and the research method(s) employed. 
Table 4. Social Media Use During Disaster Recovery Research Summary Table

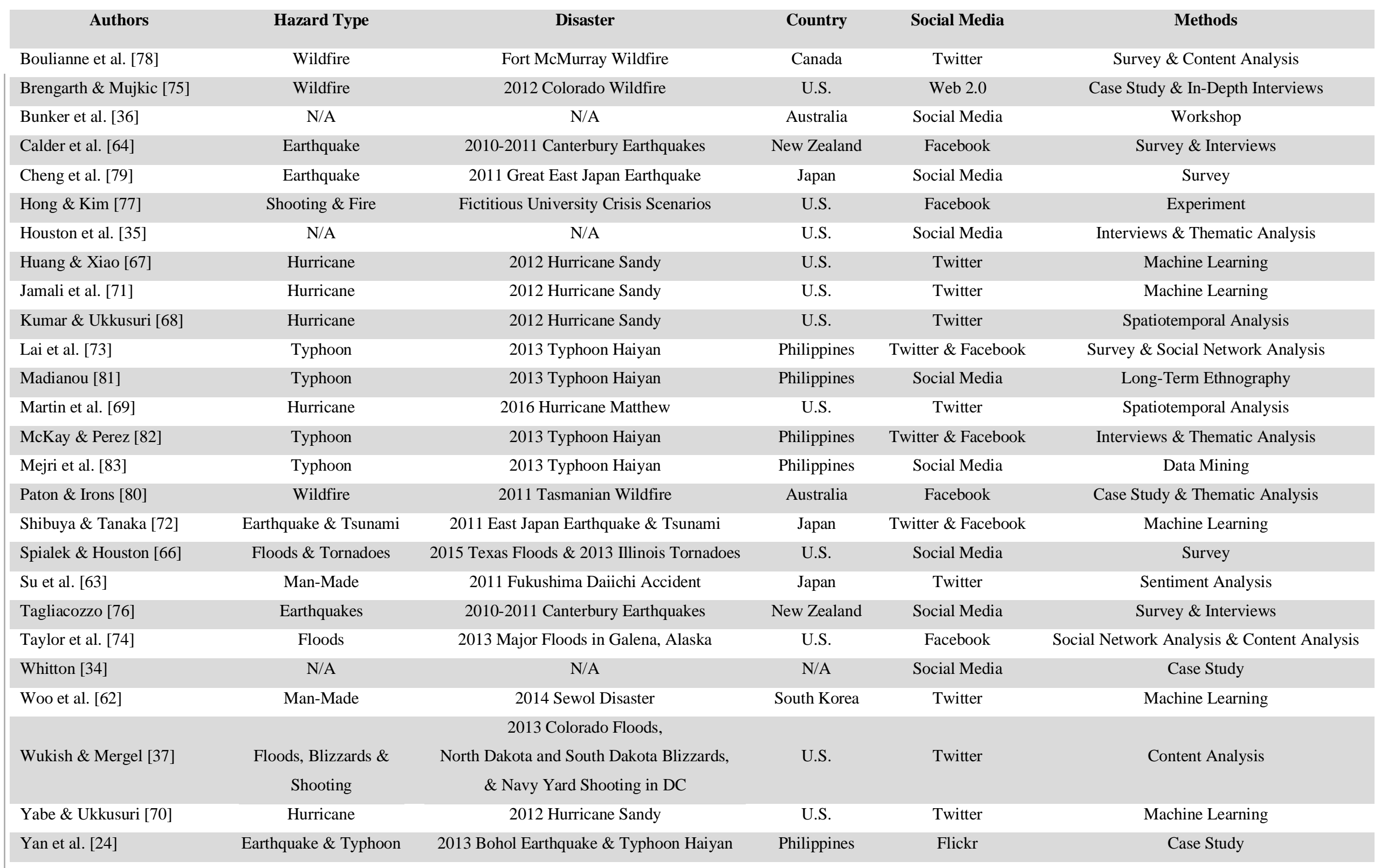




\section{Limitations of Social Media for Disaster Response and Recovery}

As illustrated by the sections above, while social media offers clear benefits to stakeholders involved in disaster response and recovery (e.g. emergency managers, relief organization, and members of the public), it is important to also discuss its limitations. Limitations raised as part of this review include missing perspectives, uncertainty in data reliability, service disruptions, data applicability, and potential negative public health outcomes. These issues will be discussed further below.

First, social media may be missing important perspectives from multiple populations. One reason for this is because social media posts contain information on and from users that opted to participate in that platform before or during the disaster. Civilian and/or emergency officials may not participate in online platforms for a variety of reasons, including personnel or financial resources, access and/or computing literacy.

Relatedly, information gleaned from social media content in any particular study was representative only of the users that created or shared content that fit within the search/filtering criteria established by the researchers conducting the study. Therefore, perspectives from the entire affected population might not be fully captured, and in turn the situational awareness developed about the incident might be biased [66, 73, 76]. It is important for the researcher to understand, to the extent practicable, the differences between social media users and the affected population. The Pew Research Center [84] issued a report stating that while the U.S. social media user base had grown more representative of the broader population in 2018, current users still did not accurately represent U.S. populations, with users tending to be younger, white, female, college educated and living in urban communities. Emergency communication efforts solely focused on social media outreach may miss reaching critical at-risk populations, such as the elderly.

Similarly, the perspectives of civilian users might be missing or mischaracterized when simply studied for one disaster event at one timepoint. Additional observations of the same populations over time; i.e., longitudinal analyses, and observations over multiple events might be required to truly understand social media usage in disasters more broadly [66].

Another limitation of using social media data as a potential source of situational awareness is that the information shared through these platforms may not be reliable. Spam bots may saturate the data with information that is inaccurate or irrelevant [85]. With the right technology, mining software, and resources, a culture shift will be necessary to reframe social media posts as data that can be relevant and trusted [86].

Also, technology that is capable of learning and predicting patterns in data is fairly new and still in development. While studies have shown progress in applying labelled data of a previous disaster to future disasters, these results were found only for general disaster-related categories [44]. Some of the topic-specific linguistic patterns might not be applicable or transportable to other content [63]. Additional work is required to further develop and validate learning patterns that apply across disasters, populations, scenarios, and cultures. 
Other limitations of social media use for disaster response involve service disruptions. The Internet may not be available immediately after a disaster takes place, or even for some time after the event. Significant infrastructure damage may affect which populations have access to social media platforms, including emergency managers. Further, victims in need of assistance and emergency managers coordinating search and rescue operations may not have the time to wait for Internet service to be reinstated before engaging in these activities.

Finally, despite the potential benefits of social media for positive mental health outcomes in the case of disaster recovery, research has also found that the use of these platforms may also result in negative mental health outcomes. For instance, a recent study conducted by Primack et al. [87] found that U.S. young adults with higher levels of social media use, including the time and frequency of use of eleven different platforms, reported feeling more socially isolated, especially in contrast with peers who indicated lower levels of use. Similarly, other studies found that adolescents who reported higher rates of social media use also experienced poor sleep quality, lower self-esteem and higher levels of anxiety and depression [88].

\section{Practical Considerations for Social Media Use for Response and Recovery}

This section presents recommendations gleaned from the literature on the best ways to leverage social media tools for optimizing emergency management. First, guidelines for social media use in disaster response are presented, followed by guidelines for social media use in disaster recovery. Then, existing research gaps in these areas are outlined. Practitioners and researchers are encouraged to work in tandem to address these gaps for more effective use of social media for disaster response and recovery in the future.

\subsection{Practical Considerations for Disaster Response}

The guidelines listed in this section are based on the research findings presented in the previous sections of this report. Similarly, these recommendations are organized by the thematic structure of the findings. Namely, the first set of guidelines correspond to best practices already identified by researchers. The second set of guidelines involves outlining areas of opportunity that have yet to be realized by emergency managers. Finally, the third set of guidelines focuses on recommendations that build on the existing usage of social media on behalf of the general public.

\subsubsection{Application of Current Best Practices}

- $\quad$ Social media use policies should exist and be accessible to all team members responsible for communication efforts. These guidelines should outline rules and best practices, staffing and resources, as well as social media post templates [32].

- Videos, maps, infographics and other types of visual materials are the preferred modality to communicate complex information [23]. These materials can be prepared beforehand so they are ready to be shared when they become relevant during disaster response.

- A robust network of social media followers should be developed long before a disaster happens. This means that emergency management organizations should have 
an online presence and be engaging with audiences during periods of nonemergencies as well as during and after disasters [40].

- Emergency managers should use social media channels during and shortly after disasters to share information. This includes updates about the event, warnings, and calls-to-action (i.e., protective action recommendations) [41].

- When uncertainty is high and rumors begin to circulate online, emergency managers can use social media to address them directly. Priority should be given to prominent/popular rumors or those that can cause the most damage if left unaddressed. Further, social media has features that can help with the issue of information quality or credibility. For example, the Facebook Live feature or the Periscope $^{4}$ application can be used to stream videos in real time. This can help emergency managers glean insight for better situational awareness [39].

- If specific information is needed for response coordination, emergency managers can articulate this need in social media. Research shows that people are eager to contribute to formal emergency management information needs on social media [58].

\subsubsection{Innovation Opportunities}

- Industry and academic researchers should partner with emergency managers to develop user-friendly tools for situational awareness [31]. A first step can be to identify current obstacles in social media use for disaster response. Then, solutions can be developed to address these challenges in a safe, accessible, ethical, and userfriendly way.

- Awareness should be raised about the most effective ways in which the general public can contribute to situational awareness. For example, social media users could be encouraged to temporarily allow geotagging of their disaster-related posts via privacy settings, if amenable, to facilitate their use by emergency officials [57].

- Strategic use of hashtags can help emergency managers filter social media content generated during the acute stage of a disaster [55]. Emergency management agencies and nonprofit organizations can adopt and in turn, encourage the use of certain hashtags when posting about different disaster-related topics.

\subsubsection{Public-Focused Insights}

- To ensure that disaster-related information reaches a wider audience on social media, emergency managers should develop partnerships with trusted and credible stakeholders (i.e., weather experts and enthusiasts). These users are influential information sources during disasters [40, 55].

- Previous disasters and emergencies can provide insight into which kinds of social media users became prominent in their respective social networks. Applying social network analysis techniques can help emergency managers make a list of potential partners for future emergencies [56].

\footnotetext{
${ }^{4}$ Periscope is an application that allows its users to livestream videos in real-time. Studies have shown that civilians and journalists have already used this application to share information and disaster coverage during emergencies like the Amtrak derailment in Philadelphia and the Hurricane Joaquin flooding in South Carolina [89]
} 
- Research has shown that in addition to smartphones, there are other unconventional sources of visual data that can inform situational awareness [22]. During the disaster response phase, this toolbox of visual data can be accessed (i.e., video doorbells and their applications) if the procedures for that process are already coordinated beforehand.

- The lack of constant updates that are relevant to the general public drive social media use and the development of emergent groups in these platforms. Research has shown that these groups are comprised of self-mobilized and involved members of the community [58]. Emergency managers can recruit people from these spaces for search and rescue, volunteering, donations and for matching existing needs with existing resources.

\subsection{Practical Considerations for Disaster Recovery}

The guidelines listed in this section are based on the research findings presented in this report. Similarly, these recommendations are organized by the thematic structure of the findings. The first set of guidelines corresponds to how social media can be used to positively impact mental health during the disaster recovery period. The second set of guidelines outlines how information from social media can inform and complement disaster recovery assessments. Finally, the third set of guidelines focuses on recommendations that can help emergency managers employ social media to establish, develop and maintain relationships with key publics during recovery.

\subsubsection{Post-Disaster Mental Health and Coping}

- To motivate members of the public to participate in response and relief efforts (e.g., volunteering), social media content strategies should focus on messages that illustrate care, concern, and invitations to help- since research has shown that these types of posts become popular online and that they are related to participation [78].

- Social media resonates with disaster-affected publics [79]. When choosing channel outlets for disaster recovery campaigns, official communicators should use social media as one of its dissemination channels to reduce anxiety of affected populations and to increase participation activities.

- Emergency managers can consider sentiment analysis of social media data as a costand time-effective solution to track public mood during all stages of a disaster [62, 63]. Social media content stands as an alternative for entities tasked with mental health interventions to assess the impacts of developments and breaking news updates [62].

- Other ways that emergency managers can use social media to support positive mental health outcomes of affected populations is providing a space for temporary memorializing practices for those in need [34]. 


\subsubsection{Recovery and Reconstruction Assessment}

- Emergency managers can implement machine learning techniques to identify different social media users and the kinds of topics that they prioritize during disaster recovery [67].

- Social media can provide complementary information to other and possible more onerous sources of data from disaster events (i.e., shelter records, surveys, in-depth interviews, etc.) [68-70].

- Visual content shared through social media can help with spatial planning decisions. Namely, advocating for social media users to turn on geo-tagging settings before, during, and after disasters can greatly increase the quantity and quality of the data and results [68-70].

- Emergency managers should consider social media as a mechanism to gauge recovery successes [24, 72]; however, researchers should first engage with practitioners to develop an agreed-upon set of recovery and resilience indicators.

- Social media can also be used to identify needs and match resources during recovery [71]. However, to be most effective, emergency managers may encourage affected populations to use a similar platform for these types of data exchanges.

\subsubsection{Relationship Management}

- Emergency managers, relief organizations, journalists, and other emergency organizations should consider the benefits that social media can bring to the process of relationship-building following a disaster. Workshops and other meetings can identify best practices for using social media to effectively engage with one another and with the public [35, 37, 73].

- Outreach strategies should prioritize disenfranchised and vulnerable populations so they too can benefit from the positive outcomes related to social media use during disaster recovery [81].

- Social media allows for unexpected and unconventional actors to emerge as prominent stakeholders in the relief, recovery, and reconstruction processes. Emergency managers should strive to identify them and include them in planning and reconstruction functions [82].

- Apart from sharing recovery-related information [36, 75, 76] and identifying existing needs of affected populations [74], emergency managers can also use social media to ask questions, answer questions, and involve the community in different decisionmaking processes throughout the recovery period.

\section{Future Research}

Since the advent of the first social networking site in 1997 [14] and the introduction of sophisticated mobile technology, emergency managers and researchers have embraced the opportunities that this technology presents for disaster response and recovery. This section summarizes the research gaps and opportunities highlighted across the social-mediated disaster management literature reviewed for this report. Four main research gaps were 
identified: marginalized populations, long-term recovery, non-mainstream social media platforms, and research-to-application.

The first research gap is the need to consider different publics when studying social media use during disasters. Some studies have focused on social media usages of vulnerable populations [90], and in turn more research needs to be conducted to better understand how different publics, (e.g., people with disabilities), use social media before and after an emergency [91]. Researchers also advocate for a better understanding of how technology serves or fails disenfranchised and marginalized groups [81]. Finally, studies of social media usage during disasters have mostly focused on specific countries and cultures e.g., U.S., Europe, Australia, and certain Asian countries [92], leaving room for additional research on populations in Latin America, Africa, Eastern Europe, and the Middle East.

Second, more work is needed to better understand how social media can be leveraged for long-term recovery efforts. Over the years, researchers have placed more emphasis on disaster response or short-term recovery compared with other phases of emergency management. In addition, researchers call for more work in adjacent areas such as disaster coordination and resilience, in hopes of preventing some of the more distressing effects that hazards can wreak upon communities.

Third, most of the research on social media during disasters tends to focus on a few of the current platforms, namely Facebook and Twitter. However, there are many different types of social media platforms that have been used or could be used for effective emergency management functions, including Instagram, Flickr and YouTube (See Section 3.3 of this report). Whether a platform is predominantly text-based, image-based, or even video-based may have significant implications for when it may be of best use. Apart from social media platforms, which is the focus of this report, there is also a need to explore the potential use of mobile applications for self-mobilizing, situational awareness development, and the coordination of relief resources for those affected by a disaster event.

Finally, a gap exists in the development of methods that can be used to apply findings to practice. Only a few studies (e.g., Kaufhold et al. [31]) identified ways to translate collected and mined social media data into a user-friendly and effective interface for use by emergency officials during disasters. Data mining technology seems to be moving faster than solutions for their use. Applied research can provide benefits here to see that the technology is translated into practical tools.

\section{Summary}

This report presents research that could inform guidance for communities on the creation and development of social media use strategies for disaster response and recovery purposes. The report answers the following questions regarding social media use during disaster response and recovery phases:

- What is the current status of social media use for disaster response, including use by the general public and potential challenges associated with that use?

- What is the current status of social media use for disaster recovery, including use by the general public and potential challenges associated with that use? 
Through a literature review and thematic analysis of studies pertaining to social media use during disaster response and recovery, six research themes emerged - three for each emergency management phase, respectively. Regarding disaster response, the first research theme highlights the current formal use of social media. It encompasses research that focuses on how emergency managers have used social media during response, and their perceptions about its utility. The second theme explores potential social media uses. Innovative approaches are applied to address the main obstacles that limit its use. To substantiate the insights that can be gleaned from these platforms, several studies draw a comparison between social media data and more conventional sources of situational awareness. Finally, the third research theme captures the latest insight about how the general public uses social media during disasters and emergencies.

Concerning social media use for disaster recovery, the first research theme highlights the current applications of social media to achieve positive mental health outcomes after a disaster takes place. The research focuses on how these tools can be leveraged to gauge postdisaster public sentiment and moods. It also explores their application within mental health campaigns, and as online sites for temporary memorializing practices. The second theme focuses on how social media can help emergency managers and relief organizations assess the ongoing progress of post-disaster recovery. Innovative approaches are employed to extract actionable insights from the data generated by social media users. The third research theme addresses how these channels contribute to relationship-building between and among the many stakeholders involved in disaster recovery.

Following the research themes discussed in Sec. 3 and Sec. 4, an overview of the limitations associated with social media usage in disasters is presented in Sec. 5. In turn, Sec. 6 provides practical considerations for social media use during both response and recovery phases of emergency management. Finally, the research gaps associated with social media usage in disasters were outlined in Sec. 7, concluding with the suggestion that practitioners and researchers can work in tandem to improve the effectiveness of social media in disaster response and recovery. 


\section{Acknowledgements}

The authors would like to thank Cynthia Rivas, Emily Walpole, Jiann Yang, and Nelson Bryner from NIST for a comprehensive review of the document before publication. 


\section{References}

[1] Kuligowski ED, Lombardo FT, Phan LT, Levitan ML, Jorgensen DP (2014) Final Report, National Institute of Standards and Technology (NIST) Technical Investigation of the May 22, 2011, Tornado in Joplin, Missouri. National Construction Safety Team Act Reports (NIST NCSTAR). (National Institute of Standards and Technology, Gaithersburg, MD), 3. Available at https://www.nist.gov/publications/final-reportnational-institute-standards-and-technology-nist-technical-investigation

[2] Kuligowski ED, Wakeman K (2017) Outdoor siren systems: a review of technology, usage, and public response during emergencies. (National Institute of Standards and Technology, Gaithersburg, MD), NIST TN 1950, p NIST TN 1950. https://doi.org/10.6028/NIST.TN.1950

[3] Kuligowski ED, Doermann J (2018) A review of public response to short message alerts under imminent threat. (National Institute of Standards and Technology, Gaithersburg, MD), NIST TN 1982, p NIST TN 1982. https://doi.org/10.6028/NIST.TN.1982

[4] National Oceanic and Atmospheric Administration (NOAA) (2014) Weather Related Fatality and Injury Statistics. Available at https:/www.weather.gov/hazstat/

[5] National Oceanic and Atmospheric Administration (NOAA) (2011) NWS Central Region Service Assessment Joplin, Missouri, Tornado - May 22, 2011. (National Weather Service, Central Region Headquarters, Kansas City, MO). Available at https://www.weather.gov/media/publications/assessments/Joplin_tornado.pdf

[6] Kuligowski ED, Kimball A (2018) Alerting under Imminent Threat: Guidance on alerts issued by outdoor siren and short message alerting systems. (National Institute of Standards and Technology, Gaithersburg, MD), NIST TN 2008. Available at https://www.nist.gov/publications/alerting-under-imminent-threat-guidance-alertsissued-outdoor-siren-and-short-message

[7] Drabek TE (2018) Community Processes: Coordination. Handbook of Disaster Research, Handbooks of Sociology and Social Research., eds Rodriguez H, Donner W, Trainor JE (Springer, Cham, CH), 2nd Ed., pp 521-549.

[8] National Governors’ Association (1979) Comprehensive Emergency Management: A Governor’s Guide. (U.S. Government Printing Office, Washington, D.C.).

[9] Rubin CB (2004) Emergency Management in the 21st Century: Dealing with Al Qaeda, Tom Ridge and Julie Gerberding. (The George Washington University Institute for Crisis, Disaster, and Risk Management, Washington, D.C.), 108. Available at https://raining.fema.gov/hiedu/downloads/clair\%20rubin\%20-\%20wp1.pdf

[10] Department of Homeland Security (DHS) (2011) Presidential Policy Directive 8: National Preparedness. Department of Homeland Security. Available at https://www.dhs.gov/presidential-policy-directive-8-national-preparedness 
[11] Department of Homeland Security (DHS) (2011) National Preparedness Goal. (Washington, D.C.), p 26. Available at https://www.fema.gov/pdf/prepared/npg.pdf

[12] Federal Emergency Management Agency (FEMA) (2018) National Preparedness Goal. FEMA.gov. Available at https://www.fema.gov/national-preparedness-goal

[13] Kaplan AM, Haenlein M (2010) Users of the world, unite! The challenges and opportunities of Social Media. Business Horizons 53(1):59-68. https://doi.org/10.1016/j.bushor.2009.09.003

[14] boyd DM, Ellison NB (2007) Social Network Sites: Definition, History, and Scholarship. Journal of Computer-Mediated Communication 13(1):210-230. https://doi.org/10.1111/j.1083-6101.2007.00393.x

[15] Fraustino JD, Liu B, Jin Y (2012) Social media use during disasters: A review of the knowledge base and gaps (final report, START). (Human Factors/Behavioral Sciences Division, Science and Technology Directorate, US Department of Homeland Security, College Park, MD), p 39.

[16] Public The Free Dictionary. Available at https://legaldictionary.thefreedictionary.com/Public

[17] Livingstone S ed. (2005) Audiences and Publics: When Cultural Engagement Matters for the Public Sphere (Intellect Ltd, Bristol, England; Portland, Or).

[18] Tapia AH, LaLone N, Kim H-W (2014) Run amok: Group crowd participation in identifying the bomb and bomber from the boston marathon bombing. Proceedings of the 11th International ISCRAM Conference (University Park, PA), pp 265-274.

[19] Gleit N (2017) More Ways to Support Causes. Facebook Newsroom. Available at https://about.fb.com/news/2017/03/more-ways-to-support-causes/

[20] Nowak M (2017) A New Center for Crisis Response on Facebook. Facebook Newsroom. Available at https://about.fb.com/news/2017/09/a-new-center-for-crisisresponse-on-facebook/

[21] Jurkowitz M, Hitlin M (2013) Citizen eyewitnesses provide majority of top online news videos in Oklahoma tornado disaster. Pew Research Center. Available at https://www.pewresearch.org/fact-tank/2013/05/22/citizen-eyewitnesses-providemajority-of-top-online-news-videos-in-oklahoma-tornado-disaster/

[22] Slick J (2019) Experiencing fire: A phenomenological study of YouTube videos of the 2016 Fort McMurray fire. Natural Hazards 98(1):181-212. https://doi.org/10.1007/s11069-019-03604-5

[23] Leong C, Pan S, Ractham P, Kaewkitipong L (2015) ICT-Enabled Community Empowerment in Crisis Response: Social Media in Thailand Flooding 2011. Journal of 
the Association for Information Systems 16(3):174-212.

https://doi.org/10.17705/1jais.00390

[24] Yan Y, Eckle M, Kuo C-L, Herfort B, Fan H, Zipf A (2017) Monitoring and Assessing Post-Disaster Tourism Recovery Using Geotagged Social Media Data. ISPRS

International Journal of Geo-Information 6(5):144. https://doi.org/10.3390/ijgi6050144

[25] Federal Emergency Management Agency (FEMA) (2019) Mobile App. FEMA.gov. Available at https://www.fema.gov/mobile-app

[26] Durbin S (2018) A new app connects hurricane evacuees with people willing to host the 'Uber for disasters.' Washington Post. Available at https://www.washingtonpost.com/news/capital-weather-gang/wp/2018/06/01/a-newapp-connects-hurricane-evacuees-with-people-willing-to-host-the-uber-for-disasters/

[27] Nancy (2019) How to use zello channels during a disaster. Zello Blog. Available at https://blog.zello.com/how-to-use-zello-channels-during-a-disaster

[28] Nextdoor What is Nextdoor? nextdoor.com. Available at https://nextdoor.com/footer/

[29] Nextdoor How to use Nextdoor in a natural disaster. nextdoor.com. Available at https://nextdoor.com/footer/

[30] Bergstrand F, Stenmark D (2016) Leveraging Bystander Reports in Emergency Response Work: Framing Emergency Managers Social Media Use. 2016 49th Hawaii International Conference on System Sciences (HICSS) (IEEE, Koloa, HI, USA), pp 162-171. https://doi.org/10.1109/HICSS.2016.28

[31] Kaufhold M-A, Rupp N, Reuter C, Habdank M (2019) Mitigating information overload in social media during conflicts and crises: design and evaluation of a cross-platform alerting system. Behaviour \& Information Technology:1-24.

https://doi.org/10.1080/0144929X.2019.1620334

[32] Lazreg MB, Chakraborty NR, Stieglitz S, Potthoff T (2018) Social Media Analysis in Crisis Situations: Can Social Media be a Reliable Information Source for Emergency Management Services? 27th International Conference on Information Systems Development (Lund, Sweden), p 13.

[33] Plotnick L, Hiltz SR, Kushma JA, Tapia AH (2015) Red Tape: Attitudes and Issues Related to Use of Social Media by U.S. County-Level Emergency Managers. Proceedings of the ISCRAM 2015 Conference (Kristiansand, NO), pp 182-192.

[34] Whitton S (2018) Post disaster temporary memorialising: Psychosocial considerations for disaster managers. Australian Journal of Emergency Management Monograph 2:1115.

[35] Houston JB, Schraedley MK, Worley ME, Reed K, Saidi J (2019) Disaster journalism: fostering citizen and community disaster mitigation, preparedness, response, recovery, 
and resilience across the disaster cycle. Disasters 43(3):591-611.

https://doi.org/10.1111/disa.12352

[36] Bunker D, Levine L, Sleigh A, Ehnis C, Babar A (2018) When Worlds Collide: The Importance of IS Alignment for Effective Disaster Recovery Completed Research. Twenty-Fourth Americas Conference on Information Systems (New Orleans, LA), pp 110 .

[37] Wukich C, Mergel I (2016) Reusing social media information in government. Government Information Quarterly 33(2):305-312.

https://doi.org/10.1016/j.giq.2016.01.011

[38] Dutt R, Basu M, Ghosh K, Ghosh S (2019) Utilizing microblogs for assisting postdisaster relief operations via matching resource needs and availabilities. Information Processing \& Management 56(5):1680-1697.

https://doi.org/10.1016/j.ipm.2019.05.010

[39] Banikalef A, Bataineh KA, Atoum M (2018) Exploring Facebook affordances in natural disaster: Case study of the 2018 dead sea flash floods in Jordan. International Journal of Engineering \& Technology 7(4):5001-5006. https://doi.org/doi:

10.14419/ijet.v7i4.25862

[40] Olson MK, Sutton J, Vos SC, Prestley R, Renshaw SL, Butts CT (2019) Build community before the storm: The National Weather Service's social media engagement. Journal of Contingencies and Crisis Management 27(4):359-373. https://doi.org/10.1111/1468-5973.12267

[41] Subba R, Bui T (2017) Online Convergence Behavior, Social Media Communications and Crisis Response: An Empirical Study of the 2015 Nepal Earthquake Police Twitter Project. https://doi.org/10.24251/HICSS.2017.034

[42] Bhatia P Beginning with Machine Learning. Available at https://parteekbhatia.com/2019/08/02/machine-learning-blog/

[43] McNulty E (2015) What's The Difference Between Supervised and Unsupervised Learning? Dataconomy. Available at https://dataconomy.com/2015/01/whats-thedifference-between-supervised-and-unsupervised-learning/

[44] Li H, Guevara N, Herndon N, Caragea D, Neppalli K, Caragea C, Squicciarini AC, Tapia AH (2015) Twitter Mining for Disaster Response: A Domain Adaptation Approach. Proceedings of the ISCRAM 2015 Conference, pp 1-7.

[45] DHS Science and Technology Center of Excellence (2016) Improving disaster response and recovery: Social media analytics and reporting toolkit. (US Department of Homeland Security, Washington, DC), p 1. Available at https://www.dhs.gov/sites/default/files/publications/cvada_social-media_coefactsheet_1604-508.pdf 
[46] DHS Science and Technology Center of Excellence (2018) SMART: Social media analytics and reporting toolkit. (US Department of Homeland Security, Washington, DC), p 1. Available at https://www.dhs.gov/sites/default/files/publications/841_RTech_SMART-Social-Media-Analytics-Reporting-Toolkit_FactSheet-180405-508.pdf

[47] Alam F, Ofli F, Imran M (2019) Descriptive and visual summaries of disaster events using artificial intelligence techniques: case studies of Hurricanes Harvey, Irma, and Maria. Behaviour \& Information Technology 0(0):1-31. https://doi.org/10.1080/0144929X.2019.1610908

[48] Kryvasheyeu Y, Chen H, Obradovich N, Moro E, Hentenryck PV, Fowler J, Cebrian M (2016) Rapid assessment of disaster damage using social media activity. Science Advances 2(3):1-11. https://doi.org/10.1126/sciadv.1500779

[49] Fang J, Hu J, Shi X, Zhao L (2019) Assessing disaster impacts and response using social media data in China: A case study of 2016 Wuhan rainstorm. International Journal of Disaster Risk Reduction 34:275-282. https://doi.org/10.1016/j.ijdrr.2018.11.027

[50] Kibanov M, Stumme G, Amin I, Lee JG (2017) Mining Social Media to Inform Peatland Fire and Haze Disaster Management. Social Network Analysis and Mining 7(1):30. https://doi.org/10.1007/s13278-017-0446-1

[51] Li Z, Wang C, Emrich CT, Guo D (2018) A novel approach to leveraging social media for rapid flood mapping: a case study of the 2015 South Carolina floods. Cartography and Geographic Information Science 45(2):97-110. https://doi.org/10.1080/15230406.2016.1271356

[52] Nguyen L, Yang Z, Zhu J, Li J, Jin F (2018) Coordinating Disaster Emergency Response with Heuristic Reinforcement Learning. arXiv:181105010 [cs, stat]:1-10.

[53] Du H, Nguyen L, Yang Z, Abu-Gellban H, Zhou X, Xing W, Cao G, Jin F (2019) Twitter vs News: Concern Analysis of the 2018 California Wildfire Event. 2019 IEEE 43rd Annual Computer Software and Applications Conference (COMPSAC), Vol. 2, pp 207-212. https://doi.org/10.1109/COMPSAC.2019.10208

[54] Sutton J, Palen L, Shklovski I (2008) Backchannels on the Front Lines: Emergent Uses of Social Media in the 2007 Southern California Wildfires. Proceedings of the 5th International ISCRAM Conference (Washington, D.C.), pp 1-9.

[55] Silver A, Andrey J (2019) Public attention to extreme weather as reflected by social media activity. Journal of Contingencies and Crisis Management 27(4):346-358. https://doi.org/DOI: 10.1111/1468-5973.12265

[56] Mirbabaie M, Bunker D, Stieglitz S, Deubel A (2019) Who sets the tone? Determining the impact of convergence behaviour archetypes in social media crisis communication. Information Systems Frontiers:1-13. https://doi.org/10.1007/s10796-019-09917-x 
[57] Bica M, Palen L, Bopp C (2017) Visual Representations of Disaster. Proceedings of the 2017 ACM Conference on Computer Supported Cooperative Work and Social Computing, CSCW '17. (ACM, New York, NY, USA), pp 1262-1276. https://doi.org/10.1145/2998181.2998212

[58] Pyle AS, Morgoch ML, Boatwright BC (2019) SnowedOut Atlanta : Examining digital emergence on facebook during a crisis. Journal of Contingencies and Crisis Management 27(4):414-422. https://doi.org/10.1111/1468-5973.12274

[59] Koetse M (2015) An Introduction to Sina Weibo: Background and Status Quo. What's On Weibo: Reporting Social Trends in China. Available at https://www.whatsonweibo.com/sinaweibo/

[60] Olshansky Robert B., Hopkins Lewis D., Johnson Laurie A. (2012) Disaster and Recovery: Processes Compressed in Time. Natural Hazards Review 13(3):173-178. https://doi.org/10.1061/(ASCE)NH.1527-6996.0000077

[61] American Counseling Association (ACA) Personal and pre-disposing factors related to coping with disasters/trauma. Available at https:/www.counseling.org/docs/traumadisaster/fact-sheet-8---personal-and-pre-disposing-factors.pdf?sfvrsn=3629e0b7_2

[62] Woo H, Cho Y, Shim E, Lee K, Song G (2015) Public Trauma after the Sewol Ferry Disaster: The Role of Social Media in Understanding the Public Mood. International Journal of Environmental Research and Public Health 12(9):10974-10983. https://doi.org/10.3390/ijerph120910974

[63] Su LY-F, Cacciatore MA, Liang X, Brossard D, Scheufele DA, Xenos MA (2017) Analyzing public sentiments online: combining human- and computer-based content analysis. Information, Communication \& Society 20(3):406-427. https://doi.org/10.1080/1369118X.2016.1182197

[64] Calder K, D’Aeth L, Turner S, Begg A, Veer E, Scott J, Fox C (2019) Evaluation of the All Right? Campaign's Facebook intervention post-disaster in Canterbury, New Zealand. Health Promotion International (day106). https://doi.org/10.1093/heapro/day106

[65] Foot K, Warnick B, Schneider SM (2005) Web-Based Memorializing After September 11: Toward a Conceptual Framework. Journal of Computer-Mediated Communication 11(1):72-96. https://doi.org/10.1111/j.1083-6101.2006.tb00304.x

[66] Spialek ML, Houston JB (2019) The influence of citizen disaster communication on perceptions of neighborhood belonging and community resilience. Journal of Applied Communication Research 47(1):1-23. https://doi.org/10.1080/00909882.2018.1544718

[67] Huang Q, Xiao Y (2015) Geographic situational awareness: mining tweets for disaster preparedness, emergency response, impact, and recovery. ISPRS International Journal of Geo-Information 4(3):1549-1568. https://doi.org/10.3390/ijgi4031549 
[68] Kumar D, Ukkusuri SV (2018) Utilizing geo-tagged tweets to understand evacuation dynamics during emergencies: a case study of hurricane sandy. WWW' 18 Companion: The 2018 Web Conference Companion (ACM Press, Lyon, France), pp 1613-1620. https://doi.org/10.1145/3184558.3191619

[69] Martín Y, Li Z, Cutter SL (2017) Leveraging Twitter to gauge evacuation compliance: Spatiotemporal analysis of Hurricane Matthew. PLOS ONE 12(7):e0181701. https://doi.org/10.1371/journal.pone.0181701

[70] Yabe T, Ukkusuri SV (2019) Integrating information from heterogeneous networks on social media to predict post-disaster returning behavior. Journal of Computational Science 32:12-20. https://doi.org/10.1016/j.jocs.2019.02.002

[71] Jamali M, Nejat A, Ghosh S, Jin F, Cao G (2019) Social media data and post-disaster recovery. International Journal of Information Management 44:25-37. https://doi.org/10.1016/j.ijinfomgt.2018.09.005

[72] Shibuya Y, Tanaka H (2019) Using Social Media to Detect Socio-Economic Disaster Recovery. IEEE Intelligent Systems 34(3):29-37. https://doi.org/10.1109/MIS.2019.2918245

[73] Lai C-H, She B, Tao C-C (2017) Connecting the dots: A longitudinal observation of relief organizations' representational networks on social media. Computers in Human Behavior 74:224-234. https://doi.org/10.1016/j.chb.2017.04.037

[74] Taylor KM, Hum R, Kontar YY (2016) Comparative analysis of virtual relief networks and communication channels during disaster recovery after a major flood in galena, alaska, spring 2013. Communicating Climate-Change and Natural Hazard Risk and Cultivating Resilience: Case Studies for a Multi-Disciplinary Approach, Advances in Natural and Technological Hazards Research., eds Drake JL, Kontar YY, Eichelberger JC, Rupp TS, Taylor KM (Springer International Publishing, Cham), pp 151-171. https://doi.org/10.1007/978-3-319-20161-0_10

[75] Brengarth LB, Mujkic E (2016) WEB 2.0: How social media applications leverage nonprofit responses during a wildfire crisis. Computers in Human Behavior 54:589596. https://doi.org/10.1016/j.chb.2015.07.010

[76] Tagliacozzo S (2018) Government Agency Communication during Postdisaster Reconstruction: Insights from the Christchurch Earthquakes Recovery. Natural Hazards Review 19(2):1-11. https://doi.org/10.1061/(ASCE)NH.1527-6996.0000283

[77] Hong S, Kim B (2019) Exploring social media use in university crisis communication: An experiment to measure impact on perceived crisis severity and attitudes of key publics. Journal of Contingencies and Crisis Management 27(1):61-71. https://doi.org/10.1111/1468-5973.12242 
[78] Boulianne S, Minaker J, Haney TJ (2018) Does compassion go viral? Social media, caring, and the Fort McMurray wildfire. Information, Communication \& Society 21(5):697-711. https://doi.org/10.1080/1369118X.2018.1428651

[79] Cheng JW, Mitomo H, Otsuka T, Jeon SY (2016) Cultivation effects of mass and social media on perceptions and behavioural intentions in post-disaster recovery - The case of the 2011 Great East Japan Earthquake. Telematics and Informatics 33(3):753-772. https://doi.org/10.1016/j.tele.2015.12.001

[80] Paton D, Irons M (2016) Communication, sense of community, and disaster recovery: A Facebook case study. Frontiers in Communication 1:1-12. https://doi.org/10.3389/fcomm.2016.00004

[81] Madianou M (2015) Digital Inequality and Second-Order Disasters: Social Media in the Typhoon Haiyan Recovery. Social Media + Society 1(2):1-11. https://doi.org/10.1177/2056305115603386

[82] McKay D, Perez P (2019) Citizen aid, social media and brokerage after disaster. Third World Quarterly 40(10):1903-1920. https://doi.org/10.1080/01436597.2019.1634470

[83] Mejri O, Menoni S, Matias K, Aminoltaheri N (2017) Crisis information to support spatial planning in post disaster recovery. International Journal of Disaster Risk Reduction 22:46-61. https://doi.org/10.1016/j.ijdrr.2017.02.007

[84] Pew Research Center Demographics of Social Media Users and Adoption in the United States. Pew Research Center: Internet \& Technology. Available at https://www.pewresearch.org/internet/fact-sheet/social-media/

[85] Ferrara E, Varol O, Davis C, Menczer F, Flammini A (2016) The rise of social bots. Communications of the ACM 59(7):96-104. https://doi.org/10.1145/2818717

[86] Mehta AM, Bruns A, Newton J (2017) Trust, but verify: social media models for disaster management. Disasters 41(3):549-565. https://doi.org/10.1111/disa.12218

[87] Primack BA, Shensa A, Escobar-Viera CG, Barrett EL, Sidani JE, Colditz JB, James AE (2017) Use of multiple social media platforms and symptoms of depression and anxiety: A nationally-representative study among U.S. young adults. Computers in Human Behavior 69:1-9. https://doi.org/10.1016/j.chb.2016.11.013

[88] Woods HC, Scott H (2016) \#Sleepyteens: Social media use in adolescence is associated with poor sleep quality, anxiety, depression and low self-esteem. Journal of Adolescence 51:41-49. https://doi.org/10.1016/j.adolescence.2016.05.008

[89] Fichet E, Dailey D, Robinson J, Starbird K (2016) Eyes on the ground: Emerging practices in periscope use during crisis events. Proceedings of the ISCRAM 2016 Conference (Rio de Janeiro, Brazil), p 10. 
[90] Fu K, White J, Chan Y, Zhou L, Zhang Q, Lu Q (2010) Enabling the disabled: media use and communication needs of people with disabilities during and after the Sichuan earthquake in China. International Journal of Emergency Management 7(1):75-87. https://doi.org/10.1504/IJEM.2010.032046

[91] Palen L, Hughes AL (2018) Social Media in Disaster Communication. Handbook of Disaster Research, Handbooks of Sociology and Social Research., eds Rodríguez H, Donner W, Trainor JE (Springer International Publishing, Cham), pp 497-518. https://doi.org/10.1007/978-3-319-63254-4_24

[92] Eckert S, Sopory P, Day A, Wilkins L, Padgett D, Novak J, Noyes J, Allen T, Alexander N, Vanderford M, Gamhewage G (2018) Health-related disaster communication and social media: Mixed-method systematic review. Health Communication 33(12):1389-1400. https://doi.org/10.1080/10410236.2017.1351278 